\title{
Approach to Respiratory System Involvement and the Symptom of Dyspnea in Covid-19 Disease
}

\author{
Gulsum Hilal Demir ${ }^{1(\mathbb{D})}$, Burcu Kayhan Tetik ${ }^{2(\mathbb{D})}$ \\ ${ }^{1}$ Elazı̆̆ Provincial Health Directorate, Elazı̆̆, Turkey, \\ ${ }^{2}$ Department of Family Medicine, Inonu University Medical School, Malatya Turkey
}

Copyright@ Author(s) - Available online at https://dergipark.org.tr/en/pub/mbsjohs

Content of this journal is licensed under a Creative Commons Attribution-NonCommercial 4.0 International License,

Received: 29 June 2021, Accepted: 06 December 2021, Published online: 31 December 2021

(C) Ordu University Institute of Health Sciences, Turkey, 2021

\begin{abstract}
The Covid-19 pandemic, China at the end of 2019 and was declared a global pandemic by the World Health Organization on March 11, is still a serious public health problem. The international virus taxonomy committee named this virus as SARSCoV-2 and the disease caused by the virus as Covid-19 disease. The disease is transmitted from person to person through droplets. When the infected person coughs, sneezes, or speaks, the virus found in respiratory secretions is transmitted by direct contact with the mucosa. In addition, it can be transmitted upon bringing one's hands to the mucous membranes of the mouth, nose, or eyes after hand-to-hand contact with droplets produced by the coughing and sneezing of a sick individual. The respiratory system is the system most affected by Covid-19 infection. The virus affects the respiratory system in 3 ways: acute respiratory distress syndrome (ARDS) with diffuse alveolar damage, diffuse thrombotic alveolar microvascular occlusion, and inflammatory mediator-associated airway inflammation. As a result of these 3 effects of the virus, impaired alveolar oxygenation, hypoxemia, acidosis and, consequently, dyspnea develops. Dyspnea occurs when breathing becomes disturbingly noticeable. Dyspnea is an important symptom that affects the prognosis of Covid-19 disease. The severity of the disease ranges from asymptomatic infection to critical illness. Dyspnea symptoms and respiratory system involvement are more common in critical illness. Primary care physicians should be familiar with respiratory system pathologies caused by the Covid-19 disease.

Keywords: Covid-19, Dyspnea, Pandemic
\end{abstract}

Suggested Citation: Demir GH, Tetik BK. Approach to Respiratory System Involvement and the Symptom of Dyspnea in Covid19 Disease Mid Blac Sea Journal of Health Sci, 2021; 7(3):439-445

\section{Address for correspondence/reprints:}

Gulsum Hilal Demir

Telephone number: $+90(552) 4307029$

E-mail: glsm_kara90@ @otmail.com 


\section{Introduction}

The Covid-19 pandemic, which emerged in Wuhan, China at the end of 2019 and was declared a global pandemic by the World Health Organization on March 11, is still a serious public health problem (1).

Iatrotropic stimulus, a term frequently used in family medicine, is defined as the reason that prompts a patient to seek out the care of a physician (2). Dyspnea is an important iatrotropic stimulus in Covid-19 disease. Furthermore, dyspnea is a symptom that should be alarming for family physicians. Distinctive problem-solving skills, which is one of the leaves of the WONCA tree of competencies in general practice, is the core competency that every family doctor should have. These such problem-solving skills should be used in the management of Covid-19 disease and in managing the symptom of dyspnea due to the disease. In this context, we aimed to examine in depth the respiratory system involvement in Covid19 disease and the symptom of dyspnea associated with this involvement.

\section{Taxonomy and Structural Features of the Coronavirus}

According to the classification determined by the International Committee on Virus Taxonomy (ICTV), coronaviruses belong to the Nidovirales class of the Riboviria kingdom. The virus that causes the Covid-19 disease is the SARS-CoV-2 strain belonging to the Betacoronavirus genus in the Coronaviridea family. The international virus taxonomy committee named this virus as SARSCoV-2 and the disease caused by the virus as Covid-19 disease (3).

Coronaviruses are $65-125 \mathrm{~nm}$ in diameter and contain single-stranded ribonucleic acid (RNA) and feature rod-like extensions on their surface. These viruses were named Coronavirus (crowned virus) due to these rod-like extensions, based on the Latin meaning of "corona" meaning "crown"(4).

\section{Coronavirus Infection Chain}

According to epidemiological studies, wild animals (bat?) sold in the Huanan Seafood Wholesale Market are thought to be the first source of the infection chain. The disease is transmitted from person to person through droplets. When the infected person coughs, sneezes, or speaks, the virus found in respiratory secretions is transmitted by direct contact with the mucosa. In addition, it can be transmitted upon bringing one's hands to the mucous membranes of the mouth, nose, or eyes after hand to hand contact with droplets produced by the coughing and sneezing of a sick individual. The majority of society is susceptible to the Covid-19 disease. Health workers, people over 50 years old, people with comorbidities (hypertension (HT), heart disease, diabetes mellitus (DM), malignancy, chronic obstructive pulmonary disease (COPD), kidney disease, etc.), people in care and rehabilitation centers, schools, military barracks, prisons, people living in migrant camps, and seasonal agricultural workers are especially vulnerable groups in terms of disease (5).

\section{Pathogenesis of Coronavirus}

Coronaviruses attach to the host cells via the spike $(S)$ protein on the outer surface and thus enter the cell. The $S$ protein regulates the entry of the virus into the host cell by recognizing the receptor in the target cell. The life cycle of the virus begins with the binding of the $S$ protein to the AngiotensinConverting Enzyme 2 (ACE2) receptor on the host cell surface (6). After the virus enters the host cell, viral antigens are presented to macrophages and $\mathrm{T}$ lymphocytes by antigen-presenting cells (7). Thus, the chain of inflammation, the severity of which varies according to the immune system and age of the person, develops. Infection primarily affects the innate immune system and causes the release of cytokines (IFN- $\alpha$, IFN- $\gamma$, IL-1 $\beta$, IL-6, IL-18, etc.), especially interferon (7).

\section{Clinical Symptoms of Covid-19 Disease}

The most common symptoms in Coronavirus patients are fever, malaise, and cough. According to a study conducted in China, common clinical symptoms include fever (88.7\%), cough (67.8\%), fatigue $(38.1 \%)$, dyspnea $(18.7 \%)$, sore throat $(13.9 \%)$, myalgia $(14.9 \%)$, and headache $(13.6 \%)$. In the same study, diarrhea $(3.8 \%)$ and vomiting $(5.0 \%)$ were found to be gastrointestinal symptoms of the virus (8).

\section{Laboratory Findings of Covid-19 Disease}

The most common laboratory findings in Covid19 diagnosis were found to be lymphocytopenia $(83.2 \%)$, thrombocytopenia $(36.2 \%)$, and leukopenia (33.7\%). High levels of infection markers such as Creactive protein (CRP), ALT/AST in liver function tests, and D-Dimer, have also been frequently reported.

Changes in general laboratory values are summarized in the table 1 below (9). 
Table 1. Changes in LaboratoryValues in Covid-19 Disease Lab Test Name Change in Test

Complete Blood Count Decreased lymphocyte thrombocyte count Increase in the number of leukocytes and neutrophils

\begin{tabular}{ll}
\hline CD4+ T Cell Count & Decrease \\
\hline CD8+ T Cell Count & Decrease \\
\hline Ferritin & Increase \\
\hline C Reactive Protein (CRP) & Increase
\end{tabular}

\begin{tabular}{ll}
\hline $\begin{array}{l}\text { Sedimentation } \\
\text { Rate }\end{array}$ & Increase \\
& \\
\hline Procalcitonin & Increase \\
\hline Interleukin 6 (IL-6) & Increase \\
\hline CreatinineKinase & Increase \\
\hline LactateDehydrogenase & Increase \\
& \\
\hline D-Dimer & Increase \\
\hline Troponin & Increase \\
\hline AST & Increase \\
\hline ALT & Increase
\end{tabular}

\section{Radiological Findings of Covid-19 Disease}

In Covid-19 pneumonia, bilateral, localized (especially in the middle and lower zone), peripherally weighted, irregularly boardered density increases and consolidation are seen on chest radiograph (10).

In the early stages of the disease, unilateral or bilateral subpleural ground-glass opacities are seen mainly in the lower lobes on Computed Tomography (CT). In the later stages of the disease, diffuse ground-glass opacities, interlobular and intralobular septal thickenings (curbstone appearance) and consolidations are detected with bilateral and multilobar distribution. Ground glass densities with more intense consolidation in a crescent or ring shape are called "reverse halo sign" and are frequently seen in Covid-19 disease (11).

\section{Clinical Course in Covid-19 Disease}

While mild infection is observed in $81 \%$ of symptomatic patients infected with Covid-19 disease, severe disease occurs in $14 \%$ of patients and critical illness occurs in 5\% of patients (12).

Severe disease is predominantly seen in people with advanced age and underlying comorbidities.
Studies have found that cardiovascular disease, DM, HT, chronic lung disease, cancer, chronic kidney disease, and obesity (body mass index (BMI) $\geq 30$ ) are associated with severe disease and mortality (13). The severity of the disease ranges from asymptomatic infection to critical illness. The clinical severity of Covid-19 disease is defined in 5 groups as asymptomatic, mild, moderate, severe, and critical as indicated in the table 2 below $(12,13)$.

Table 2. Clinical Course in Covid-19 Disease

\begin{tabular}{ll}
\hline Asymptomatic infection: & Cases with positive SARS-CoV-2 PCR \\
& test and noclinical symptoms. \\
& Asymptomatic infection is important \\
because it increases the risk of & transmission in the community. Especially \\
& asymptomatic infants and children play an \\
& important role in human-to-human \\
& transmission. \\
\hline Mildillness: & Patients have mild symptoms such as \\
& fever, fatigue, myalgia, sorethroat, cough, \\
& runnynose and sneezing. \\
& There are noradiographic findings. \\
\hline Moderateillness: & Pneumonia, fever and cough; patients \\
may have wheezing, but no severe \\
hypoxemia. \\
Radiographic findings are present. \\
Rapid progression, dyspnea, centra \\
lcyanosis. Inpatients: \\
Respiratory rate $>30$ \\
Oxygen Saturation (SpO2) $<93$ \\
There are signs of PaO 2/FiO2 < 300 \\
mm/Hg. \\
Akut Respiratory Distress Syndrome \\
(ARDS), respiratory failure, sepsis, septic \\
shock, multiple organ dysfunction are \\
seen. \\
\hline Critical illness:
\end{tabular}

\section{Covid-19 Disease and the Respiratory System}

The course of the Covid-19 disease in the respiratory system can be categorized as early period, pulmonary period, and hyperinflammation period. In the early period, the virus is active and causes symptoms such as dry cough, fever, and weakness. In the pulmonary period, shortness of breath and hypoxemia develop. During the hyperinflammation period, the host response is dominant. During this period, ARDS, shock, and organ failure may develop (14).

\section{Covid-19 Disease and Pneumonia}

Radiological imaging shows infiltration and ground glass opacities (20). Mild cases may present with fever, chills, and dry cough. Tachypnea (>30/min), dyspnea, respiratory distress, and hypoxia ( $\mathrm{SpO} 2<90 \%$ in room air) are seen in severe cases (15).

\section{Covid-19 Disease and ARDS}

ARDS is considered according to clinical and respiratory parameters. The diagnosis of ARDS should be considered in the presence of bilateral 
infiltration in radiology if acute respiratory distress cannot be explained by the association of cardiogenic edema. ARDS causes diffuse alveolar damage to the lung. In an acute situation, hyaline membrane formation in the alveoli, followed by interstitial enlargement, edema, and fibroblast proliferation develops (16).

\section{Covid-19 Disease and Cytokine Storms}

A cytokine storm is a severe immune system hyperreaction in which large amounts of cytokines are rapidly released into the systemic circulation. Chemokines and high plasma inflammatory cytokines, interleukins (IL-1, IL-6, IL-8, IL-12, IL18), tumor necrosis factor (TNF- $\alpha$ ), and interferon (INF) play a role in the cytokine storm. The inflammatory response caused by excessive cytokine release seen with $\mathrm{T}$ cell and monocyte/macrophage activation increases vascular permeability, leading to exudative fluid accumulation in the alveoli and causes respiratory failure (17).

Fever that does not decrease despite treatment, elevated D-dimer, high ferritin and CRP values, cytopenia, low fibrinogen, and abnormal liver function tests should suggest a cytokine storm. Looking at ferritin, CRP, liver enzymes, triglyceride, D-dimer, lymphocyte count, and platelet count values in terms of hyperinflammation in all severe Covid-19 cases; it is important to recognize the cytokine storm early and to identify the subgroups that may benefit from immunosuppression (5).

\section{Treatment of Covid-19 Disease}

\section{Favipravir}

Favipiravir is recommended in probable or definite cases in the Covid-19 treatment guide of the Ministry of Health. In asymptomatic, uncomplicated, mild-to-moderate pneumonia patients, a 5-day treatment is recommended as $2 \times 1600 \mathrm{mg} / \mathrm{day}$ on the first day and $2 \times 600 \mathrm{mg} / \mathrm{day}$ on the next 4 days. In cases aged $>50$ years and with comorbidities, a total of 10 days of treatment is recommended, with the dose of Favipravir being $2 \times 1800 \mathrm{mg}$ on the first day and $2 \times 800$ on the other days (18).

\section{Anticoagulant Therapy}

Thrombosis prophylaxis should be applied in all hospitalized Covid-19 patients unless there is active bleeding or thrombocytopenia $(<25-30.000 / \mu 1)$. Low molecular weight heparin (LMWH) is preferred over standard heparin in thrombosis prophylaxis. Because LMWH causes thrombocytopenia less commonly
(18).

\section{Other Treatments:}

Oxygen therapy, steroid therapy, Tocilizumab, and plasma therapy can be applied to hospitalized patients.

\section{Definition of Dyspnea}

While breathing is an unnoticed condition in normal physiology, when it becomes disturbingly noticeable, it is called dyspnea (19). It describes the feeling of difficulty in breathing. The word dyspnea is formed by the combination of the words "dys" meaning bad or difficult and "pnea" meaning breath or breathing. It is a subjective term and people may express dyspnea in different ways. Patients may express the symptoms of dyspnea as shortness of breath, chest tightness, panting, and air hunger.

The mechanisms involved in the formation of dyspnea sensation are as follows:

Increased respiratory demand: Increased ventilation at vigorous exercise levels in healthy individuals, and even mild exercise in patients with lung and heart disease causes dyspnea. This increased effort stimulates the central nervous system, resulting in an increase in motor stimulation. The dyspnea cycle results in decreased activity, decreased fitness, even less movement, and occurrence of dyspnea*. Age, nutritional disorders, and hypoxemia due to disease also cause a decrease in exercise capacity (20).

Abnormalities of the respiratory muscles: Weakness or mechanical failure of the respiratory muscles causes an incoordination between the central motor response and lung ventilation. This disharmony explains the dyspnea that occurs in neuromuscular diseases and respiratory muscle fatigue. In those with COPD, excessive inflammation of the lung and increased enlargement of the thorax lead to shortening of the inspiratory muscles and reduced pressure-generating effect. The decrease in the mechanical strength of the inspiratory muscles creates the feeling of dyspnea (20).

Conditions that prevent breathing: Increased airway resistance with narrowing of the airways in diseases such as asthma and COPD, and decreased lung elasticity in lung parenchymal diseases such as pulmonary fibrosis cause dyspnea. The emergence of conditions that prevent breathing results in central motor commands trying to increase ventilation. 
Dyspnea occurs when increased respiratory effort cannot provide the necessary ventilation (20).

Blood gas abnormalities: Blood gas disorders are one of the most serious conditions to occur in heart and lung diseases. Hypoxemia increases the motor activity of respiration via chemoreceptors. Hypoxia also has a direct dyspnea-causing effect (20).

Dyspnea can also be classified as acute and chronic. Acute dyspnea develops within minutes to hours. It mostly happens in diseases that affect the heart or lungs. Pericardial tamponade and pneumothorax are examples of acute dyspnea that life threatening and often need urgent treatment. Chronic dyspnea is dyspnea lasting longer than one month. Chronic dyspnea is usually progressive. Initially, shortness of breath with exertion may increase over time and can be felt without exertion. COPD and asthma are the most common examples of chronic dyspnea (20)

\section{The Symptom of Dyspnea in Covid-19 Disease}

The respiratory system is the system most affected by the Covid-19 infection. The virus affects the lungs in 3 ways: acute respiratory distress syndrome with diffuse alveolar injury (ARDS), diffuse thrombotic alveolar microvascular occlusion, and airway inflammation associated with inflammatory mediators. As a result of these 3 effects of the virus, impaired alveolar oxygenation, hypoxemia, acidosis, and dyspnea develop as a result. (21).

Dyspnea is an important symptom affecting the prognosis of Covid-19 disease. In their metaanalysis study, which included 13 studies and 3027 patients, Zheng et al. categorized the disease as critical/mortal and non-critical. Dyspnea symptoms were significantly higher in patients categorized as critical/mortal (22). In another meta-analysis study in which 4062 patients were examined, statistically significant data was found suggesting that patients who were old, male, had a high BMI, and had dyspnea and fever symptoms experienced a more severe form of the illness (23). In a study conducted by Xie et al. in Wuhan, $49.2 \%$ of Covid-19 patients had dyspnea symptoms. As a result of this study, researchers found an independent relationship between shortness of breath and death (24). In another meta-analysis study conducted by Jain et al., in which they examined 1813 patients; dyspnea was found to be the only predictive symptom for severe Covid-19 disease and ICU admission (25).

There are studies in the literature showing that
Covid-19 disease causes both acute and chronic dyspnea in patients. (26.27) In a cohort study by Lerum et al., in which they followed 103 Covid-19 patients for 3 months, it was found that dyspnea continued in $56 \%$ of the patients after 3 months. As a result of this research, they thought that Covid-19 might be the cause of chronic dyspnea (28).

\section{The Concept of Non-Dyspneic Hypoxemia} (Happy Hypoxemia, Silent Hypoxemia) in Covid19 Disease

Hypoxemia is an insufficient amount of $\mathrm{O} 2$ in the arterial blood $(\mathrm{PaO} 2<80 \mathrm{mmHg})$. In diseases such as pneumonia, COPD, and asthma, hypoxemia in the blood is usually seen along with the symptom of dyspnea. Likewise, in Covid-19 disease, hypoxemia is seen in the blood together with dyspnea. Silent hypoxemia (Happy hypoxemia) is severe hypoxemia without symptoms of dyspnea (29). Some COVID19 patients have been labelled with 'happy hypoxia', in which patient complaints of dyspnoea and observable signs of respiratory distress are reported to be absent. A perplexing clinical aspect of COVID-19 is presentation of patients with pronounced hypoxemia without expected signs of respiratory distress or dyspnea, even when cyanotic. Nonetheless, these patients frequently leapfrog clinical evolution stages and suffer ARDS with concomitant cardiorespiratory arrest and death. This phenomenon is referred to as silent or 'happy' hypoxemia. Although the prevalence is not clear in Covid-19 Disease, silent hypoxemia can also be seen. There are many hypotheses in the literature regarding the pathophysiology of silent hypoxemia that can be seen in Covid-19 disease. Inability to stimulate the respiratory center due to insufficient increase in $\mathrm{CO} 2$ in the blood, the fact that the coronavirus binds to ACE receptors in peripheral chemoreceptors and desensitizes them, and its the relationship to thrombi in the pulmonary vessels are among the hypotheses of silent hypoxemia that occurs without the feeling of dyspnea $(30,31,32$, $33,34)$.

In Summary, How Should Primary Care Physicians Approach Respiratory System Involvement and the Sympton of Dyspnea in Covid19 Disease?

In a newly diagnosed or follow-up Covid-19 patient, shortness of breath should be questioned in the taking of medical history. Among the vital signs, respiratory rate and oxygen saturation should be checked. Patients with respiratory rate $>30$ and oxygen saturation $<93$ should be referred to a higher 
level of care. In addition, since one of the causes of dyspnea in Covid-19 disease is microvascular thrombosis, the use of anticoagulants should be questioned, and anticoagulants should be started in patients who do not use anticoagulants by using the coagulopathy management guide of the Ministry of Health. In regards to the blood test results of the patient; if the blood lymphocyte count is approximately $10 \mathrm{x}$ the upper limit of the normal value or ferritin $>500 \mathrm{ng} / \mathrm{ml}$ or D-dimer $>1000 \mathrm{ng} / \mathrm{ml}$ or CRP > approximately 10x the upper limit of the normal value, the patient should be referred to an upper level of care on suspicion of cytokine storm (5.9) Physicians should not forget that in Covid-19 disease, patients may have hypoxemia without symptoms of dyspnea, and should be alert to silent hypoxemia.

In Turkey, covid-19 follow-up is not done so comprehensively by primary care physicians. However, these recommendations should be taken into account by primary care physicians.

Peer-review: Externally peer-reviewed.

Author Contributions: Concept: G.H.D, B.K.T, Design: G.H.D, B.K.T Literature Search: G.H.D, Data Collection and Processing: G.H.D, B.K.T, Analysis and/or Interpretation: G.H.D, B.K.T, Writing: G.H.D, B.K.T

Conflict of Interest: No conflict of interest was declared by the authors.

Financial Disclosure: The authors declared that this study hasn't received no financial support.

\section{References}

1. WHO Director-General's opening remarks at the media briefing on COVID-19 - 11 March 2020, World Health Organization (WHO), https://www.who.int/dg/ speeches/detail/ whodirector-general-s-opening-remarks-atthe-mediabriefing-on-covid-19-11-march2020, (erişimtarihi: 01.05.2021).

2. J.AndréKnottnerus, Betweeniatrotropic stimulus and interiatric referral: the domain of primary care research,Journal of Clinical Epidemiology,Volume 55, Issue 12,2002,Pages 1201-1206,ISSN 0895-4356

3. Coronaviridae Study Group of the International Committee on Taxonomy of Viruses, the species severe acute respiratory syndrome-related coronavirus: classifying 2019-nCoV and naming it SARS-CoV-2, Nat Microbiol 2020 Apr;5(4):536-544. doi: 10.1038/s41564-0200695-z. Epub 2020 Mar 2
4. McIntosh K, Dees JH, Becker WB, Kapikian AZ, Chanock RM. Recovery in tracheal organ cultures of novel viruses from patients with respiratory disease. Proc Natl Acad Sci USA 1967;57:933-40.

5. T.R. Ministry of Health, General Directorate of Public Health: COVID-19 (SARS-CoV-2 INFECTION) GUIDE. Scientific BoardStudy, T.C. Ministry of Health 12 April 2020, Ankara

6. Indwiani Astuti and Ysrafil, Severe Acute Respiratory Syndrome Coronavirus 2 (SARSCoV-2): An overview of viral structure and host response, Diabetes MetabSyndr. 2020; 14(4): 407-12.

7. Li G, Fan Y, Lai Y, Han T, Li Z, Zhou P. Coronavirus infections and immune responses. $\mathrm{J}$ Med Virol. 2020;92:424-32

8. Jing Yang, Ya Zheng, Xi Gou, Prevalence of comorbidities and its effects in patients infected with SARS-CoV-2: a systematic review and meta-analysis, Int J Infect Dis. 2020;94:91-95

9. Rodriguez-Morales AJ, Cardona-Ospina JA, Gutiérrez-Ocampo E, Latin American Network of Coronavirus Disease 2019-COVID-19 Research (LANCOVID-19). Electronic address: https://www.lancovid.org. Clinical, laboratory and imaging features of COVID-19: A systematic review and meta-analysis. Travel Med Infect Dis. 2020;34:101623.

doi: 10.1016/j.tmaid.2020.101623. Epub 2020 Mar 13.

10.Wong HYF, Lam HYS, Fong AH, Leung ST, Chin TW, Lo CSY, et al.. Frequency and Distribution of Chest Radiographic Findings in Patients Positive for COVID-19. Radiology. 2020;296(2):E72-E78.

doi: 10.1148/radiol.2020201160. Epub 2020 Mar 27

11.Bernheim A. Mei X. Huang M. Chest CT findings in coronavirus disease-19 (COVID-19): relationship to duration of infection. Radiology. 2020:200463

12. Wu Z, McGoogan JM. Characteristics of and important lessons from the coronavirus disease 2019 (COVID-19) outbreak in China: summary of a report of 72314 cases from the Chinese Center for Disease Control and Prevention. Jama. 2020;323(13):1239-1242.

13.Wang Y, Wang Y, Chen Y, Qin Q. Unique epidemiological and clinical features of the emerging 2019 novel coronavirus pneumonia (COVID-19) implicate special control measures. J Med Virol. 2020;1-9: 10.1002/jmv.25748 
14.Zhou M, Zhang X, Qu J. Coronavirus disease 2019 (COVID-19): a clinical update. (2020) Front Med. 2020; 2. doi: 10.1007/s11684- 0200767-8.

15.Gattinoni L, Chiumello D, Rossi S. (2020). COVID-19 pneumonia: ARDS or not? Crit Care, 24(1): 154. doi:10.1186/s13054-020- 02880-Z

16.Xu Z, Shi L, Wang Y, Zhang J, Huang L, Zhang C, Liu S, Zhao P, Liu H, Zhu L, Tai Y, Bai C, Gao T, Song J, Xia P, Dong J, Zhao J, Wang FS. Pathological findings of COVID-19 associated with acute respiratory distress syndrome. Lancet Respir Med. 2020;8(4):420-422. doi: 10.1016/S2213-2600(20)30076-X.

17. Wong CK, Lam CWK, Wu AKL, Plasma inflammatorcytokines and chemokines in severeacute respiratory syndrome. Clin ExpImmun, 2004;136(1):95-103.4

18. Ministry of Health, COVID-19 Adult Treatment Algorithm. Access date: 9 May 2021. Available from: https://covid19.saglik.gov.tr

19.Braithwaite S, Perina D. Dyspnea. In: Marx CA, editor-in-chief. Rosen's emergency medicine: concepts and clinical practice, 7 th ed. Philadelphia: Mosby Incorporated; 2010.

20.American Thoracic Society. Dyspnea Mechanisms, assessment, and management: A consensus statement. Am J Respir Crit Care Med 1999; 159:321-40

21.Pathological findings of COVID-19 associated with acute respiratory distress syndrome. Lancet Respir Med. 2020;8(4):420-22. doi: 10.1016/S2213-2600(20)30076-X.

22.Zheng Z, Peng F, Xu B, Zhao J, Liu H, Peng J, Li Q, Jiang C, Zhou Y, Liu S, Ye C, Zhang P, Xing Y, Guo H, Tang W. Risk factors of critical \& mortal COVID-19 cases: A systematic literature review and meta-analysis. J Infect. 2020 Aug;81(2):e16-e25.

doi: 10.1016/j.jinf.2020.04.021. Epub 2020 Apr 23.

23.Xu L, Mao Y, Chen G. Risk factors for 2019 novel coronavirus disease (COVID-19) patients progressing to critical illness: a systematic review and meta-analysis. Aging (Albany NY). 2020;12(12):12410-12421. doi:10.18632/aging.103383

24.Xie J, Covassin N, Fan Z, Singh P, Gao W, Li G, et al. Association Between Hypoxemia and Mortality in Patients With COVID-19. Mayo Clin Proc. 2020;95(6):1138-47. doi: 10.1016/j.mayocp.2020.04.006. Epub 2020 Apr 11.
25.Jain V, Yuan JM. Predictive symptoms and comorbidities for severe COVID-19 and intensive care unit admission: a systematic review and meta-analysis. Int J Public Health. 2020;65(5):533-546. doi:10.1007/s00038-02001390-7

26.Erbay A, Long COVID: A New Definition, Bozok Tip Derg 2020;10(4):111-114

27. Carfî A, Bernabei R, Landi F; for the Gemelli Against COVID-19 Post-Acute Care Study Group. Persistent Symptoms in Patients After Acute COVID-19. JAMA. 2020;324(6):603-605.

28.Lerum TV, Aaløkken TM, Brønstad E, Aarli B, Ikdahl E, Lund KMA, et.al. Dyspnoea, lung function and CT findings three months after hospital admission for COVID-19. Eur Respir J. 2020 Dec 10:2003448. doi: 10.1183/13993003.03448-2020. Epub ahead of print. PMID: 33303540; PMCID: PMC7736755

29. Tobin MJ, Laghi F, Jubran A. Why COVID-19 Silent Hypoxemia Is Baffling to Physicians. Am J Respir Crit Care Med. 2020 Aug 1;202(3):356360. doi: 10.1164/rccm.202006-2157CP.

30.Brouqui P, Amrane S, Million M, Cortaredona S, Parola P, Lagier JC, et. al. Asymptomatic hypoxia in COVID-19 is associated with poor outcome. Int J Infect Dis. 2021;102:233-238. doi: 10.1016/j.ijid.2020.10.067.

31.Banzett RB, Similowski T, Brown R.Addressing respiratory discomfort in the ventilated patient Tobin MJ.editor. Principles and practice of mechanical ventilation 3rd ed New York: McGraw-Hill Inc.2012;1265-1280.

32. Tobin MJ, Laghi F, Jubran A. Why COVID-19 Silent Hypoxemia Is Baffling to Physicians. Am J Respir Crit Care Med. 2020;202(3):356-360. doi: 10.1164/rccm.202006-2157CP

33.Nouri-Vaskeh M, Sharifi A, Khalili N, Zand R, Sharifi A. Dyspneic and non-dyspneic (silent) hypoxemia in COVID-19: Possible neurological mechanism. Clin Neurol Neurosurg. 2020;198:106217.

doi: 10.1016/j.clineuro.2020.106217. Epub 2020 Sep 9. PMID: 32947193;

34.Machado-Curbelo C. Silent or 'Happy' Hypoxemia: An Urgent Dilemma for COVID-19 Patient Care. MEDICC Rev. 2020;22(4):85-86. doi: 10.37757/MR2020.V22.N4.9. 